\title{
Synthesis of Titanium Carbide from Woody Materials by Self-Propagating High Temperature Synthesis
}

\author{
Tatsuya ASHITANI, Ryuichi TOMOSHIGE,* Masafumi OYADOMARI, Tomoko UENO and Kokki SAKAI \\ Graduate School of Bioresource and Bioenvironmental Sciences, Kyushu University, 6-10-1, Hakozaki, Higashi-ku, Fukuoka-shi $812-8581$ \\ * Research Center for Advances in Impact Engineering, Faculty of Engineering, Sojo University, 4-22-1, Ikeda, Kumamoto-shi $860-0082$
}

\author{
自己伝ぱ高温合成法による木質原料由来の炭化チタンの合成 \\ 芦谷竜矢 ·友重竜一 $*$ 親泊政二三 ·上野智子 ·坂井克己 \\ 九州大学大学院生物資源環境科学研究科, 812-8581 福岡市東区箱崎 6-10-1 \\ *崇城大学工学部衝撃先端技術研究センター, 860-0082 熊本市池田 4-22-1
}

\begin{abstract}
Woody waste materials were used for the preparation of titanium carbide ceramics (TiC) by utilizing combustion synthesis or self-propagating high temperature synthesis (SHS). The outer and inner barks and wood of the sugi (Cryptomeria japonica) were used to react with titanium powder as raw materials, as well as commercially available reagents of cellulose and lignin. It was detected by X-ray diffractometry that the TiC phase was obtained directly arose from the mixture of the woody waste materials and titanium powder, without formation of any major oxide phase. Broadening of half width and shift in diffraction peaks of the obtained TiC phase suggest that the TiC phase included lattice deformation and had a non-stoichiometric composition. This latter observation may imply the release of carbon, i.e., formation of carbon mono- or dioxide. The carbide phase had a mean particle size of $1-5 \mu \mathrm{m}$, and showed a shape similar to a TiC synthesized from a mixture of graphite and titanium powders. The combustion velocity of the mixtures tended to increase with the relative amount of carbon included in the woody materials. On the other hand, the velocity indicated a tendency to decrease with hydrogen and oxygen contents in the materials, which resulted from an endothermic reaction, accompanied with pyrolysis of the woody waste materials during SHS reaction.
\end{abstract}

[Received December 13, 2001; Accepted April 18, 2002]

Key-words : TiC, SHS reaction, Wood, Bark, Cellulose, Lignin

1. Introduction

A large amount of wood has accumulated in forests in the world, and has been used for many purposes such as house building, furniture making, pulp production, etc. Especially, it is well known, that sugi (Cryptomeria japonica D. Don), a conifer species, has been used as one of the major wood resources in Japan. However, when the tree is peeled or processed for various usages mentioned above, a large quantity of barks and sawdust are generated. The sugi bark occupied a large proportion of woody wastes in Japanese domestic sawmills. As most of the bark is treated as useless residue, we have disposed of the bark by dumping and burning. The disposal must have ever led to unfavorable air pollution and the accumulation of massive waste materials. If we had found some appropriate treatment methods for the bark and sawdust, we would have been able to reduce destruction of the environment.

Here, one of the unique processes for reuse of wood was reported by Okabe et al. ${ }^{1)}$ They attempted to prepare $\mathrm{C}-\mathrm{C}$ composites from wood, called as "wood ceramics" by using an electric or induction furnace. The preparing process consisted of impregnation of the wood with phenol resin under vacuum at high temperature.

On the other hand, various carbides, such as $\mathrm{TiC}$ and $\mathrm{SiC}$, are used as industrial ceramics, e.g., cutting tools, ceramic heaters, abrasives, and so on. They also have high melting points with extremely hardness, and indicate excellent electric conductivities. Ota et al. ${ }^{2}$ ) and Greil et al. ${ }^{3)}$ reported that $\mathrm{SiC}$ and various metal carbides from a carbonized wood were obtained by an infiltration process. However, these synthesis methods mentioned above require a large amount of energy and certain special equipment, which are not economical and not simple.

Recently, many workers have reported that self-propagat- ing high temperature synthesis (SHS) or combustion synthesis could be applied to readily produce various ceramics or composites with high melting points. ${ }^{4)-6)}$ One of the authors also reported that carbide, boride, nitride, and their composites could be easily obtained under atmospheric pressure at room temperature by SHS reaction without using expensive devices such as electric and induction furnaces.7)-9) Especially, TiC was easily prepared from metal titanium powder and graphite or activated charcoal powder, because of more reaction activity of titanium.

In the present study, we have attempted to utilize the whole woody waste materials as a carbon source for a synthesis of TiC ceramics. If the synthesis is possible, application as material of abrasives may be expected for the TiC synthesized from woody materials. Another purpose of this study is to find dependency of reactivity on different components evolved in the woody waste material, which are cellulose and lignin of major components of mature plants. Especially, the sugi outer bark contains more lignin-like components than the inner bark and wood. ${ }^{10)}$ Whereas, the bark contains condensed tannin, here, tannin can be regarded as a compound similar to lignin in this study.

\section{Experimental procedures}

Woody waste materials of the outer and inner barks and wood as carbon source materials were obtained from a 42 year-old sugi tree grown in Kyushu University Forest, Fukuoka, Japan. After the bark was peeled from the sugi tree, the brown-colored outer bark was separated from the beige-colored inner bark with a knife. The barks and the wood were ground to comminute under 80 mesh by a Willey mill. Moreover, commercially available reagents of graphite (Aldrich Chemical Co., Inc., Milwaukee, USA), cellulose (Toyo Roshi Kaisha, Ltd., Tokyo) and lignin (Tokyo Kasei 
Kogyo Co., Ltd., Tokyo) were also used, comparing with an experimental result used the woody waste materials. Titanium powder (TSP-150, mean particle size: $45 \mu \mathrm{m}$, Sumitomo Sitix Co., Ltd., Hyogo) was used as another raw material.

The woody waste material and titanium powder were drymixed in a mortar for $1 \mathrm{~h}$ at a fixed molar ratio of $\mathrm{C} / \mathrm{Ti}=1$. The carbon content included in the woody materials was measured by elemental analysis (CHN carder MT-5, Yanako), which was done after drying them at $105^{\circ} \mathrm{C}$ for 12 $\mathrm{h}$. This analysis was reflected to weigh exactly the woody materials against metal powder to be $\mathrm{C} / \mathrm{Ti}=1$.

The mixed powder was tapped into a mild steel container with a cylindrical hole of $20 \mathrm{~mm}$ in diameter and $30 \mathrm{~mm}$ in height, as illustrated in Fig. 1. An adiabatic sheet of $1 \mathrm{~mm}$ thick, consisting mainly of crysotaile of a kind of serpentine, was inserted between the powder mixture and the steel container. The SHS reaction was initiated under atmospheric pressure at room temperature by passing an electric current at about $0.5 \mathrm{kVA}$ for $5 \mathrm{~s}$ through a tungsten coil (wire diameter: $0.45 \mathrm{~mm}$ ). The coil was placed at the top portion of the powder mixture. Velocity of the combustion wave, i.e. reaction rate, was also measured using a thermocouple placed at the bottom of the cylindrical hole. The distance, $x$, between the tungsten heating-coil and the top end of the thermocouple, as well as the time, $t$, the combustion wave took to travel this distance through the powder mixture were measured. The combustion wave velocity was calculated by dividing $x$ by $t$. For comparison, the velocity of the mixture of graphite and titanium powders was also measured.

X-ray diffraction experiments (XRD; source of the X-rays: $\mathrm{Cu} \mathrm{K} \alpha$, RAD-1B, Rigaku Co., Tokyo) were per-

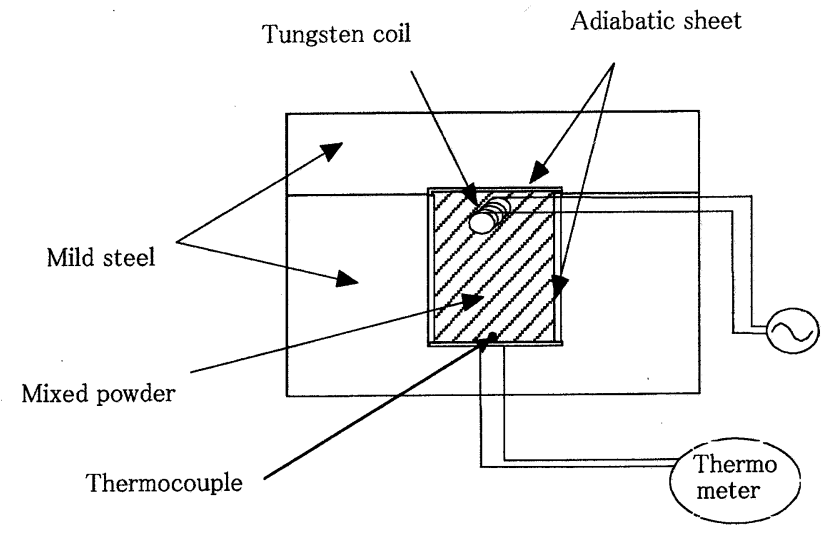

Fig. 1. Schematic illustration of container for SHS reaction. formed on diffraction angles from 30 to $120^{\circ}$ and at a scan rate of $2 \%$ min. The X-ray peak angles were corrected by using a silicon standard sample. Microstructural observations of the woody materials and synthesized materials were conducted by a scanning electron microscope (SEM; JSM6301F, JEOL Ltd., Tokyo) after sputtering with gold. Measurements by thermogravimetric and differential thermal analyzer (TG/DTA320, Seiko Instruments Inc.) were performed for various woody waste materials and the mixtures of the woody waste materials with titanium powder from 30 to $1300^{\circ} \mathrm{C}$ under argon atmosphere. Heating rate in the measurement was $40^{\circ} \mathrm{C} / \mathrm{min}$.

\section{Results and discussion}

3.1 Chemical analysis of the woody waste materials

The empirical formulae derived from the elemental analysis of woody materials are listed in Table 1 . It is found that lignin has the maximum relative carbon content. The relative carbon content decreases in order of lignin, outer bark, wood powder, inner bark and then the cellulose.

3.2 X-ray diffractometry and SEM observations

Figure 2 shows SEM micrographs of the woody materials. Both inner and outer barks (Figs. 2(a) and (b)) and the wood powder (Fig. 2(c)) had rod-shaped structures. Cellulose and lignin had needle-like structure and granular-like structure, respectively (Figs. 2(d) and (e)). Figure 3 shows a result of SEM microscopy on the products obtained from the woody materials and titanium. Each sample had grain size of about 1 to $5 \mu \mathrm{m}$. The size was much smaller than those of the wood materials and cellulose powders as shown in Fig. 3. The structures of the wood material powder were not held in the products. Further, the products showed that shapes of their particle were similar to that of $\mathrm{TiC}$ synthesized from the mixture of graphite and titanium powders. In microstructure of the product obtained from woody materials, small pores were observed between crystal grains in the product. This small pore was similarly observed in the TiC synthesized from charcoal activated powders and titanium. ${ }^{11)}$ It was suggested strongly that the pores might be formed during SHS, and that formation of the pores was due to generation of carbon mono- or dioxide.

X-ray diffraction patterns of the various products are shown in Fig. 4. In most of the reaction products, only the $\mathrm{TiC}$ phase was detected without any major oxide phases. On the other hand, a minor titanium peak was detected in the lignin-derived products. In comparing the diffraction pattern of the products from the woody waste materials-metal system with that from the graphite-titanium, we found that the peaks of $\mathrm{TiC}$ phase synthesized from the woody materials shifted slightly to higher diffraction angle. Deviation in the diffraction peak angle was listed in Table 2. The largest deviation was observed in a sample from cellulose-titanium system. The carbide derived from lignin indicated peak shift

Table 1. Results of Elemental Analysis for Woody Materials

Content of Oxygen was Culuculated by Subtracting Carbon and Hydrogen Contents from 100

\begin{tabular}{cccccc}
\hline & \multicolumn{5}{c}{ Content / mass \% } \\
\cline { 2 - 6 } Element & Outer bark & Inner bark & Wood & Cellulose & Lignin \\
\hline Carbon & 51.6 & 46.3 & 48.5 & 42.7 & 54.6 \\
Hydrogen & 5.43 & 5.64 & 6.21 & 6.23 & 4.44 \\
Oxygen & 42.9 & 48.1 & 45.4 & 51.1 & 40.9 \\
\hline Empirical formura & $\mathrm{C}_{1.0} \mathrm{H}_{1.3} \mathrm{O}_{0.63}$ & $\mathrm{C}_{1.0} \mathrm{H}_{1.4} \mathrm{O}_{0.78}$ & $\mathrm{C}_{1.0} \mathrm{H}_{1.52} \mathrm{O}_{0.71}$ & $\mathrm{C}_{1.0} \mathrm{H}_{1.8} \mathrm{O}_{0.90}$ & $\mathrm{C}_{1.0} \mathrm{H}_{0.97} \mathrm{O}_{0.59}$ \\
\hline
\end{tabular}




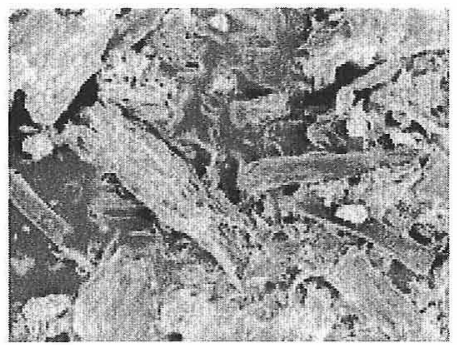

(a)

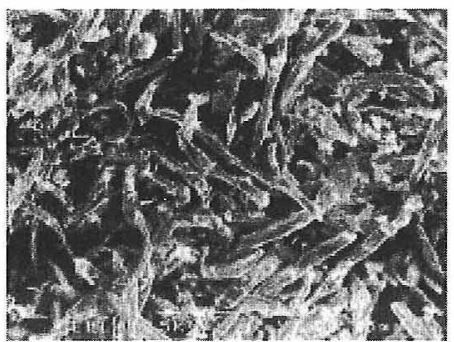

(d).

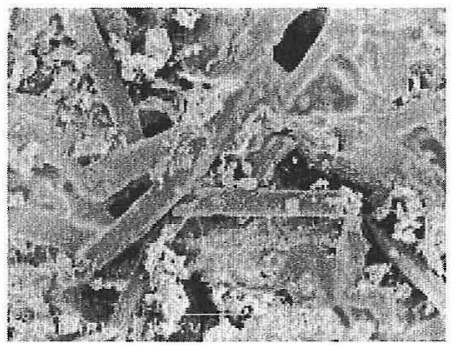

(b)

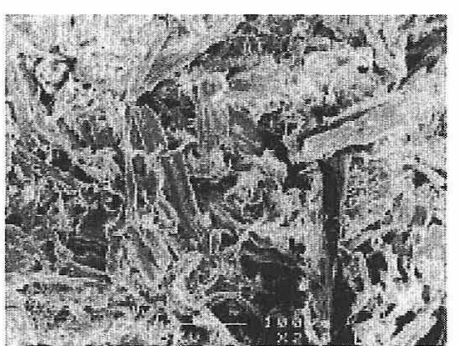

(C)

Fig. 2. SEM micrographs of outer bark (a), inner bark (b), wood (c), cellulose (d) and lignin (e).

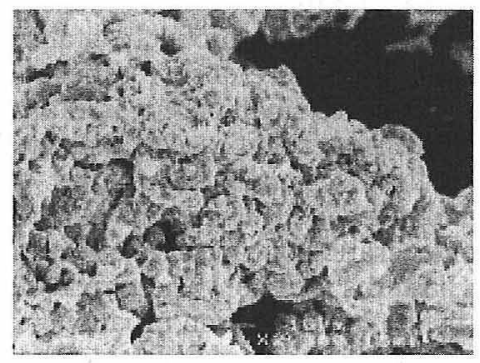

(a)

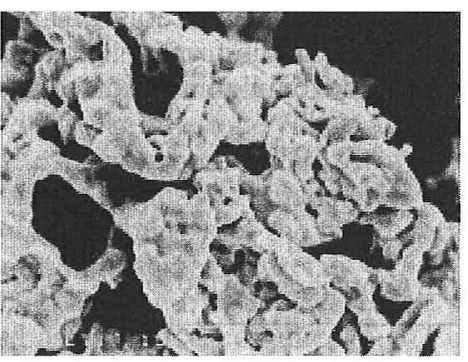

(d)

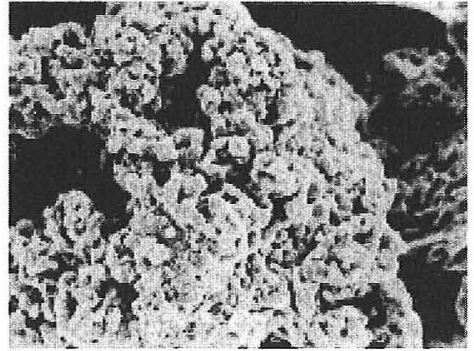

(C)

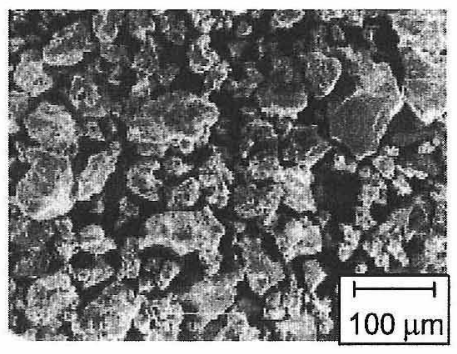

(e) 
rowest half width values, respectively, among the woody waste material systems.

TiC product from the outer bark indicated the half width

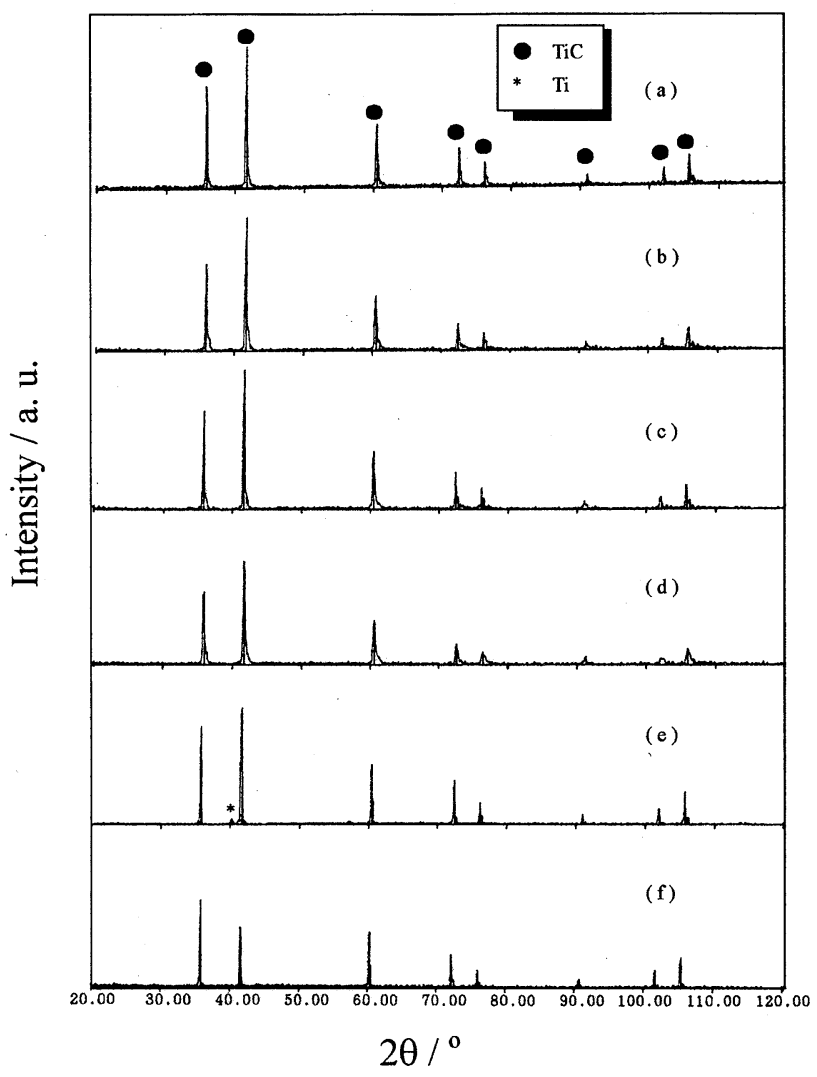

Fig. 4. X-ray diffraction patterns of products prepared from outer bark (a), inner bark (b), wood (c), cellulose (d), lignin (e) and graphite (f). wider than that of the product from lignin. Consequently, TiC from graphite showed the narrowest half width in all of the products, because it is considered that graphite had the least oxygen among these carbon sources. It is known that the narrow half width in diffraction peaks suggests a sound crystal with less lattice distortions and defects. Thus, it is speculated that $\mathrm{TiC}$ from graphite hardly had lattice distortions and defects. Here, one of the authors reported previously transmission electron microscopy (TEM) of TiC synthesized from a mixture of titanium and charcoal activated powders. ${ }^{11)}$ Charcoal activated is a kind of carbon material containing a small quantity of oxygen. As a result, it was found that diffraction spots of stoichiometric $\mathrm{TiC}_{1.0}$ consisted only of fundamental spots. With changing the molar ratio of carbon to titanium, super lattice reflection was observed at $(1 / 21 / 21 / 2)$ and its equivalent site between the fundamental spots for non-stoichiometric $\mathrm{TiC}_{0.8}$ and $\mathrm{TiC}_{0.6}$ in addition to the fundamental spots. Furthermore, diffuse scattering was observed probably due to the short-range order structure of carbon vacancy. This previous report suggests strongly that the same phenomena could have been also caused in the woody waste material-titanium system in the present study, because the woody waste materials include some of oxygen as well as charcoal activated.

Therefore, it is considered that lignin system, which had a small quantity of oxygen, was easy relatively to form stoichiometic $\mathrm{TiC}$ compound with less lattice defects.

3.3 Combustion velocities

Results of combustion velocities for various mixtures are shown in Fig. 5. It seems that the results relate to the relative carbon content listed in Table 1.

According to both the results, the combustion velocities increased with the relative carbon contents included in the woody materials. For example, the fastest and the slowest velocities were represented in the reaction systems containing lignin and cellulose, respectively. Since it is expected that reaction activity in $\mathrm{TiC}$ synthesis depends on the number of direct reaction sites between titanium and carbon component included in the woody waste materials, cellulose, or lignin, these results must have been appropriate.

Table 2. Peak Shifts Peaks to Higher Angles of Several in X-ray Diffraction Patterns of TiC from SHS Reaction (for TiC from Graphite)

\begin{tabular}{cccccc}
\hline & \multicolumn{5}{c}{ Peak shift $/ \circ$} \\
\cline { 2 - 6 } $2 \theta_{(\text {hkl) }}$ & Outer bark & Inner bark & Sugi wood & Cellulose & Lignin \\
\hline $105^{\circ}(420)$ & 0.42 & 0.50 & 0.42 & 0.65 & 0.34 \\
\hline $76^{\circ}{ }_{(222)}$ & 0.26 & 0.26 & 0.26 & 0.43 & 0.17 \\
\hline $72^{\circ}(311)$ & 0.26 & 0.26 & 0.26 & 0.44 & 0.24 \\
\hline
\end{tabular}

Table 3. Half Value Widths of Several Peaks in X-Ray Diffraction Patterns of TiC from SHS Reaction

\begin{tabular}{ccccccc}
\hline & \multicolumn{6}{c}{ Half value widths $/ \circ$} \\
\cline { 2 - 7 } $2 \theta_{(\mathrm{hkl})}$ & Outer bark & Inner bark & Sugi wood & Cellulose & Lignin & Graphite \\
\hline $105^{\circ}(420)$ & 0.30 & 0.38 & 0.32 & 0.61 & 0.25 & 0.23 \\
\hline $76^{\circ}(222)$ & 0.27 & 0.30 & 0.28 & 0.67 & 0.22 & 0.15 \\
\hline $72^{\circ}(311)$ & 0.26 & 0.38 & 0.38 & 0.50 & 0.22 & 0.15 \\
\hline $41^{\circ}(200)$ & 0.26 & 0.26 & 0.26 & 0.31 & 0.24 & 0.20 \\
\hline
\end{tabular}




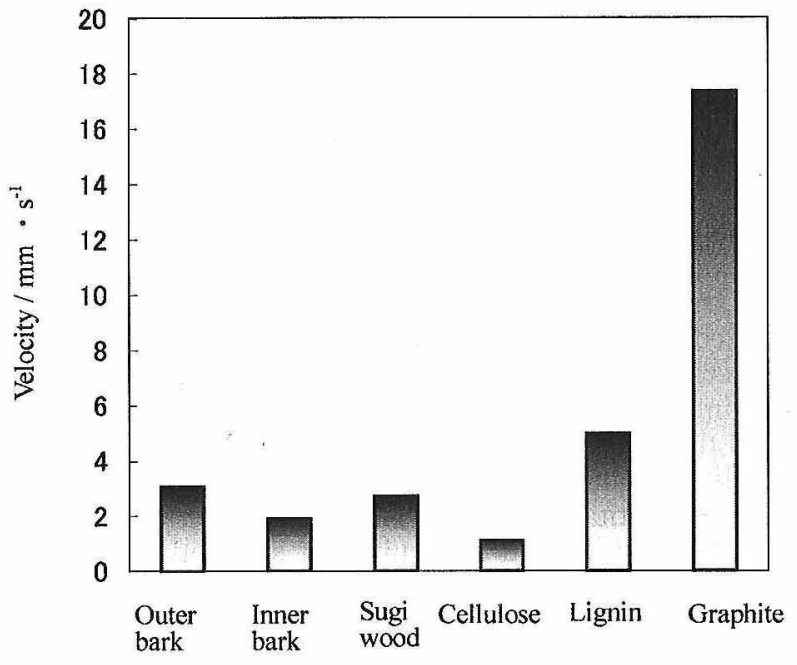

Carbon source

Fig. 5. Combustion velocity in SHS reaction using different carbon source.

Here, a little water was observed near the product after SHS reaction. From this phenomena, it was speculated that source of the generated water was at interior of the woody waste materials. That is, the water could be formed from oxygen and hydrogen composed the wastes. In addition, the water might affect the combustion velocity, because a reaction accompanied with formation the water would reduce the adiabatic temperature of combustion.

\subsection{Reaction mechanism}

It is important to consider a reaction mechanism between the woody materials and titanium.

The SHS reaction proceeds under high temperature. Therefore, it is speculated that an early stage in the reaction of woody materials with titanium is pyrolysis process of the woody waste materials, followed by formation of $\mathrm{TiC}$ by the reaction of the pyrolysis products with titanium. The pyrolysis behavior of the woody waste materials was observed by TG. Figures 6 and 7 show results of the TG and DTA measurements for various woody raw materials, respectively. It was observed that decomposition of lignin occurred at higher temperature (from 750 to $800^{\circ} \mathrm{C}$ ) than that of any other materials, accompanied with weight loss. The weight loss might be due to formation of carbon mono- or dioxide, or water. After the measurements, some of the residue remained. In contrast, cellulose was decomposed rapidly around $350^{\circ} \mathrm{C}$. As for weight loss, the cellulose system was greater than lignin system. Both the bark and wood systems were situated between the greatest and the least systems.

The TG curves of mixture of woody raw materials and titanium were similar to Fig. 6 . On the other hand, results of DTA measurements for mixture of woody raw material and titanium are shown in Fig. 8. Exothermic reaction at $760^{\circ} \mathrm{C}$ was observed in lignin-titanium system. This exothermic peak was not observed in Fig. 7. In contrast, only endothermic reaction at $350^{\circ} \mathrm{C}$ was observed in cellulose-titanium system. The bark-titanium and the wood-titanium systems were also situated between the cellulose and the lignin systems as well as weight loss.

Here, it is known that the combustion velocity is dependent generally on an adiabatic temperature of combustion, $T_{\text {ad. }}$. For example, the velocity become very fast if the adiabatic temperature is high in a certain reaction system. ${ }^{11)} \mathrm{TG}$ measurements revealed generation of endotherm in the

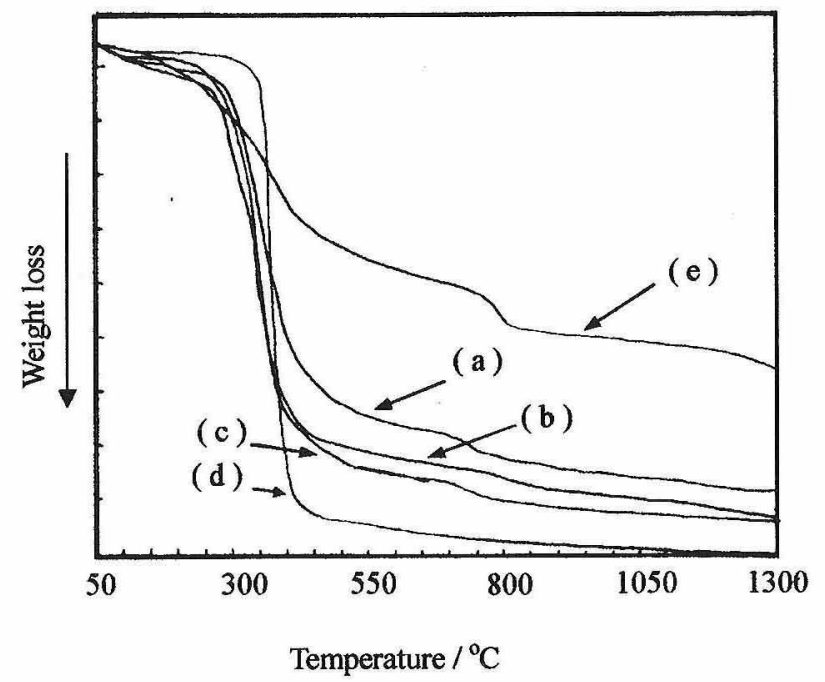

Fig. 6. TG curves of outer (a) and inner (b) barks, wood (c), cellulose (d) and lignin (e).

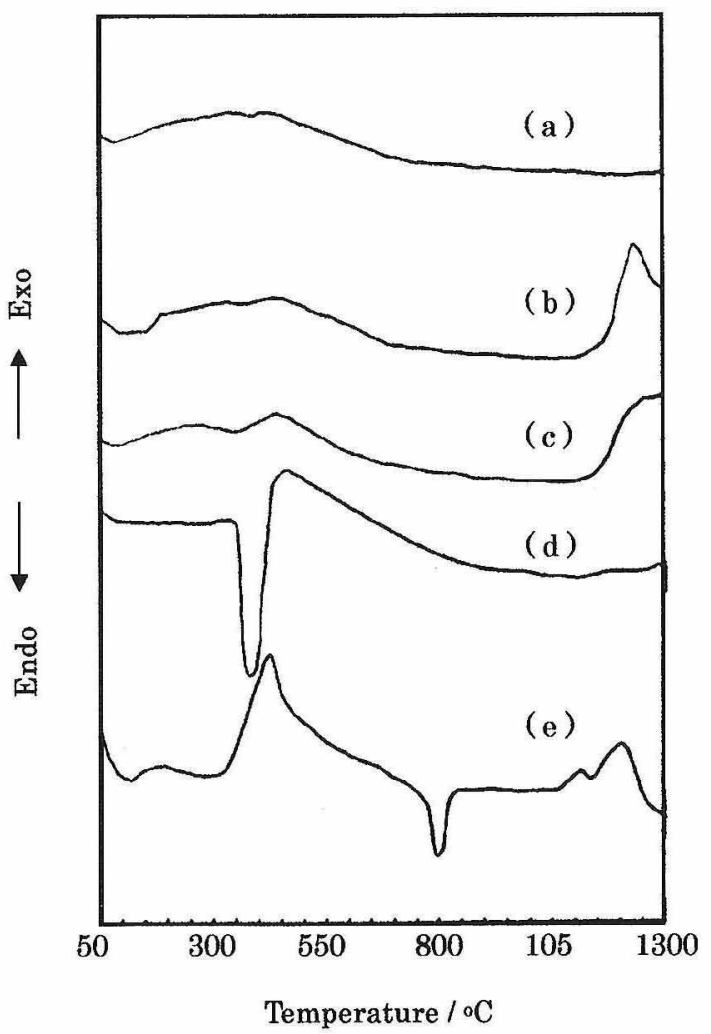

Fig. 7. DTA curves of outer (a) and inner (b) barks, wood (c), cellulose (d) and lignin (e).

reaction system of cellulose with titanium mentioned above. Considering these results, it can be recognized that the combustion velocity decreased due to the endothermic reaction accompanied with formation of water. However, because the exothermic reaction was occurred in the lignin-titanium system, the combustion velocity decreased hardly, comparing to the cellulose-titanium system.

It must be good way to consider a behavior of each element in the woody waste materials for understanding the reaction mechanism during SHS reaction. Hydrogen in the 


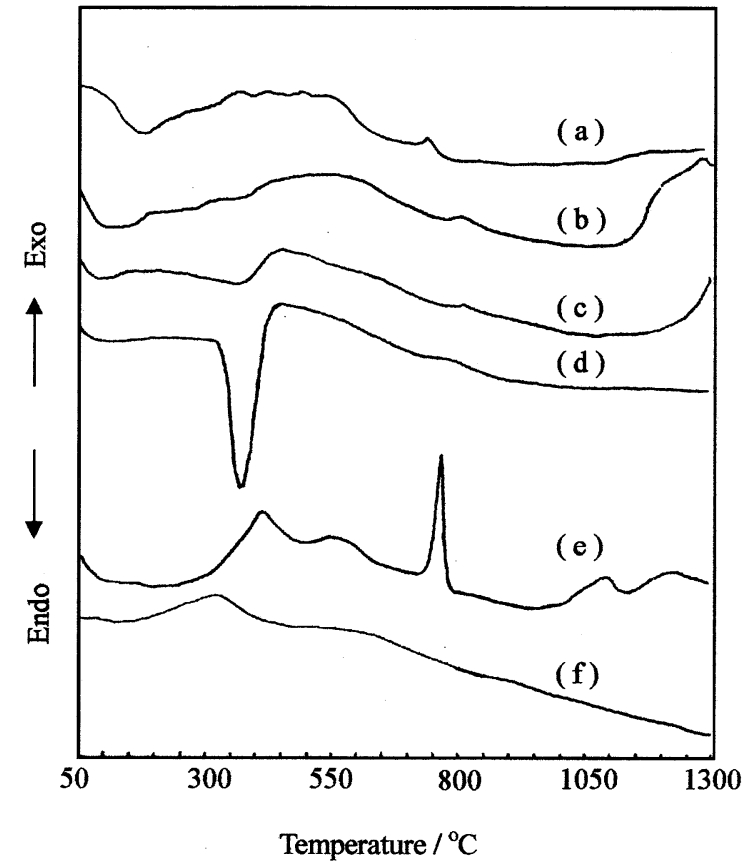

Fig. 8. DTA curves of titanium with outer (a) and inner (b) barks, wood (c), cellulose (d), lignin (e) and graphite (f).

woody waste materials should be eliminated from them due to formation of water accompanied with a reaction with oxygen contained in the wastes during SHS reaction. Most of oxygen contained in the wastes could be eliminated as water as well, and should be also released as carbon dioxide or monoxide. X-ray diffraction chart of a residue obtained after TG-DTA in titanium- woody waste materials is shown in Fig. 8. Titanium oxide (TiO) and titanium was detected in the residue. On the other hand, it was revealed by X-ray analysis that no reaction occurred in the graphite-titanium system. In both cases, though maximum measurement temperature was $1300^{\circ} \mathrm{C}$ and heating rate was $40^{\circ} \mathrm{C} / \mathrm{min}$, no TiC phase was detected. From these results, it is considered that following reactions would occur during the TG-DTA measurements for mixture of woody raw material and titanium.

$$
\begin{aligned}
& \text { Woody raw materials } \\
& \stackrel{\mathrm{C}}{\longrightarrow}+\mathrm{H}_{2} \mathrm{O} \uparrow+\mathrm{CO} \uparrow \text { or } \mathrm{CO}_{2} \uparrow \text { [pyrolysis] (1) } \\
& \mathrm{Ti}+\mathrm{O} \text { (from woody raw materials) } \longrightarrow \mathrm{TiO}(2)
\end{aligned}
$$

In the cellulose-titanium system, it is thought that Reaction (2) was not so predominant, because the amount of the titanium oxide formed was less than that in the lignin-titanium system, as shown in Fig. 9. On the other hand, Reaction (2) was predominant in the lignin-titanium reaction system, because pyrolysis of lignin occurred at higher temperature than that of the other materials (Fig. 8). It is considered that exothermic peak at $760^{\circ} \mathrm{C}$ observed in Fig. 8 indicate the formation of $\mathrm{TiO}$.

However, in the SHS system, it is considered that the reaction contained pyrolysis and $\mathrm{TiC}$ formation takes place instantaneously.

$$
\begin{aligned}
& \text { Woody raw materials }+\mathrm{Ti} \\
& \longrightarrow \mathrm{TiC}+\mathrm{H}_{2} \mathrm{O} \uparrow+\mathrm{CO} \uparrow \text { or } \mathrm{CO}_{2} \uparrow
\end{aligned}
$$

The formation of carbon dioxide or monoxide in the Reactions of (3) could lead to formation of $\mathrm{TiC}$ phase with nonstoichiometric composition. Thus, it is suggested that introduction of the lattice defect into TiC crystals arises from the abstraction of carbon by oxygen atoms existed in woody

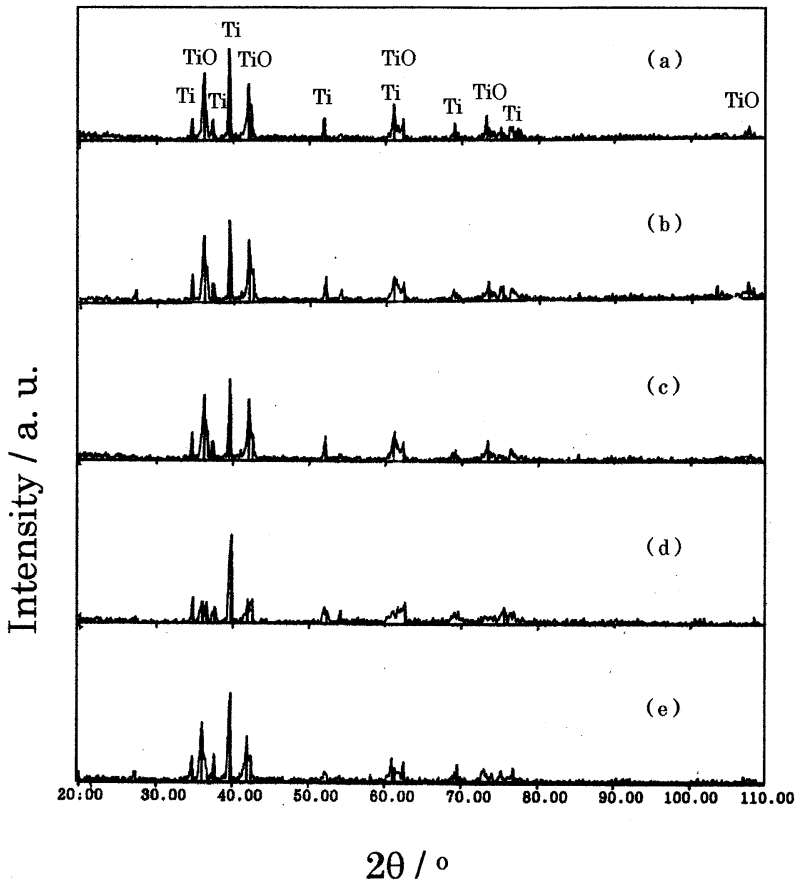

Fig. 9. X-ray diffraction patterns of residue obtained after TGDTA in titanium with outer (a) and inner (b) barks, wood (c), cellulose (d) and lignin (e).

materials, and release of carbon oxide was predominant in oxygen rich and hydrogen poor material. On the other hand, release of carbon oxide was not predominant in material as lignin, which had a small quantity of oxygen.

This abstraction of carbon by oxygen is noticeable when the woody material is used as carbon source in preparation of $\mathrm{TiC}$ by using SHS reaction.

\section{Conclusion}

We found it possible to quickly and readily synthesize TiC by SHS reaction utilizing only the woody waste materials as carbon sources without carbonization process. Although it was difficult to demonstrate the exact reaction process in this experiment due to its short reaction time, the reaction mechanism could be hypothesized by considering the compositional ratio and the structure of components contained in the raw materials.

Then, conclusions are summarized below:

(1) SEM observations showed that $\mathrm{TiC}$ from the woody materials had the grain size of about 1 to $5 \mu \mathrm{m}$.

(2) X-ray diffraction experiments revealed that $\mathrm{TiC}$ from lignin had the least lattice distortion and defects, and that $\mathrm{TiC}$ from cellulose had more. However, TiC with the least lattice distortion and defects were produced from the outer bark among the used natural materials.

(3) The combustion velocities were considerably promoted by using the woody materials having more carbon content. Whereas the velocities were suppressed by the materials involving more hydrogen and oxygen components.

(4) It was suggested that the introduction of the lattice distortion and defect into the $\mathrm{TiC}$ crystals arose from the abstraction of carbon by the oxygen atom existed in the woody waste materials.

\section{References}

1) “Wood Ceramics," Ed. by Okabe, T., Uchida Rokakuho (1985) pp. 2-40 [in Japanese]. 
2) Ota, T., Takahashi, M., Hibi, T., Ozawa, M., Suzuki, S. and Hikichi, Y., J. Am. Ceram. Soc., 78, 3409-11 (1995).

3) Greil, P., Lifka, T. and Kaindl, A., J. Eur. Ceram. Soc., 18, 1961-73 (1998).

4) Munir, Z. A., Am. Ceram. Soc. Bull., 67, 342-49 (1998).

5) Munir, Z. A. and Anselmi-Tamburini, U., Mater. Sci. Rep., 3, 277-365 (1989).

6) Choi, Y. and Rhee, S., J. Mater. Res., 9, 1761-66 (1994).

7) Tomoshige, R., Kakoki, Y., Chiba, A., Imamura, K. and Matsushita, T., J. Ceram. Soc. Japan, 103, 634-38 (1995).
8) Tomoshige, R. and Matsushita, T., J. Ceram. Soc. Japan, 104, 94-100 (1996).

9) Tomoshige, R. and Murayama, A. and Matsushita, T., J. Am. Ceram. Soc., 80, 761-64 (1997).

10) Ueno, T., Geng, X., Ashitani, T., Oyadomari, M. and Sakai, K., Mokuzai Gakkaishi, 47, 260-66 (2001).

11) Tomoshige, R., Kakoki, Y., Chiba, A., Imamura, K. and Matsushita, T., Proceedings of the 1995 International Conference on Metallurgical and Materials Apprications of ShockWave and High-Strain-Rate Phenomena (1995) pp. 67-74. 